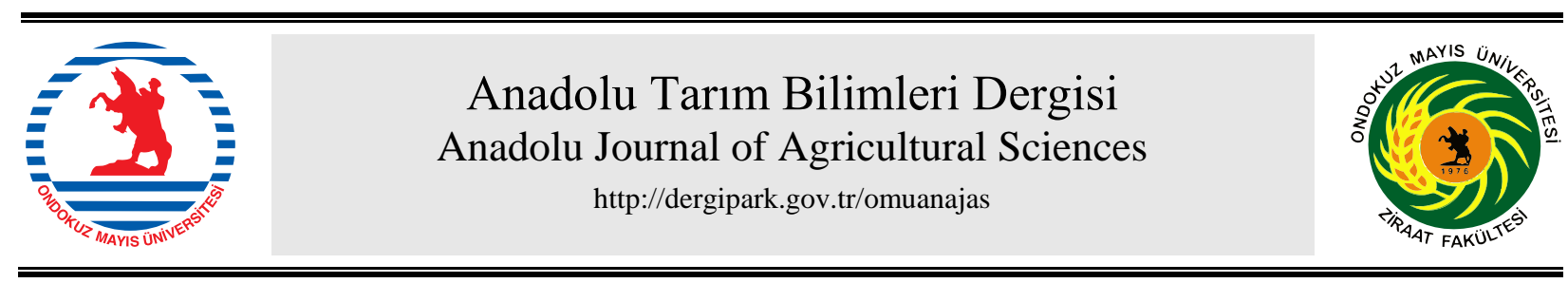

Araştırma/Research

Anadolu Tarım Bilim. Derg./Anadolu J Agr Sci, 34 (2019)

ISSN: 1308-8750 (Print) 1308-8769 (Online) doi:10.7161/omuanajas.551680

\title{
Işık ve sıcaklığın topraksız tarım koşullarında salkım domatesin meyve kalitesine etkisi
}

\author{
Melek Özkaplan*, Ahmet Balkaya \\ Ondokuz Mayıs Üniversitesi, Ziraat Fakültesi, Bahçe Bitkileri Bölümü, Samsun \\ *Sorumlu yazar/corresponding author: melek.ozkaplan@ omu.edu.tr
}

Geliş/Received 10/04/2019 Kabul/Accepted 11/06/2019

\begin{abstract}
ÖZET
Bu çalışmada, topraksız tarımda domates yetiştiriciliğinde farklı 1şık ve sıcaklık koşullarının meyve kalitesi üzerine olan etkileri incelenmiştir. Araştırma; 2014 (ilkbahar ve sonbahar) ve 2015 (ilkbahar) yılları arasında cam serada oluşturulan gölgeli ve gölgesiz koşullar altında, Hindistan cevizi lifi ve kayayünü yetiştirme substratlarında yürütülmüştür. Bitkisel materyal olarak, Bandita $\mathrm{F}_{1}$ domates çeşidi kullanılmıştır. Çalışmada meyve kalite unsurları olarak meyve boyu (mm), meyve çapı (mm), meyve şekil indeksi, meyve kabuk ve meyve et rengi (L, a, b, hue ${ }^{\circ}$ ve chroma*), toplam asitlik (TA), suda çözünebilir kuru madde (SÇKM, \%), meyve eti sertliği, meyve suyu elektiriksel iletkenliği (EC) ve pH değerleri incelenmiştir. Araştırma sonucunda; Bandita $\mathrm{F}_{1}$ salkım domates yetiştiriciliğinde meyve kalite parametrelerinin $16.42-26.22^{\circ} \mathrm{C}$ sıcaklık ve $96.10-455.93 \mu \mathrm{mol} \mathrm{m}^{-2} \mathrm{~s}^{-1} 1$ şı şiddeti sınırlarında, kullanılan Hindistan cevizi lifi ve kayayünü yetiştirme substratlarına bağlı olarak değişkenlikler gösterdiği belirlenmiştir. Tüm uygulamalar içerisinde; en yüksek ortalama meyve boyu (52.02 mm), meyve çap1 (62.12 mm) ve meyve şekil indeksi (0.83) değerleri 2015 yılı ilkbahar dikim döneminde elde edilmiştir. Hindistan cevizi lifi substratının; meyve kabuk rengi; L, a, b, hue ${ }^{\circ}$ ve chroma* değerleri üzerine olumlu yönde etkili olduğu saptanmıştır. Çalışmada, $24.60{ }^{\circ} \mathrm{C}$ sıcaklık ve $432.67 \mu \mathrm{mol} \mathrm{m} \mathrm{m}^{-2} \mathrm{~s}^{-1}$ 1şık şiddeti koşullarında en yüksek SÇKM değeri (\%5.66) elde edilmiştir. Artan sıcaklık ve 1şık şiddetinin, domateste \% SÇKM değerini olumlu yönde artırdı̆̆ 1 belirlenmiştir. Araştırma sonucunda, $16.42{ }^{\circ} \mathrm{C}$ sıcaklık ve $96.10 \mu \mathrm{mol} \mathrm{m} \mathrm{m}^{-1}$ 1şık şiddeti koşullarında, domates meyvelerinde en fazla toplam asit oranı (\%0.44) elde edilmiştir. Domates meyvelerinin titre edilebilir asitlik değeri, azalan 1şık şiddetiyle artış göstermiştir. Araştırma sonucunda; tüm meyve kalite parametreleri birlikte değerlendirildiğinde yüksek 1şık (432.67-455.93 $\left.\mu \mathrm{mol} \mathrm{m} \mathrm{m}^{-2}\right)$, yüksek sıcaklık (24.60-26.22 ${ }^{\circ} \mathrm{C}$ ) koşullarının ortalama meyve boyu, meyve çap1, meyve şekil indeksi, meyve suyu EC ve pH değerleri gibi meyve kalite unsurını olumlu yönde etkilediği saptanmıştır. Ayrıca, Hindistan cevizi lifi substratının topraksız tarımda yetiştirme ortamı olarak öne çıktığı belirlenmiştir.
\end{abstract}

The effects of light and temperature on the fruit quality parameters of cluster tomatoes growing in soilless culture

\footnotetext{
ABSTRACT

In this study, the effects of different light and temperature conditions on fruit quality of tomatoes grown in soilless culture were investigated. The research carried out at between 2014 (spring and autumn) and 2015 (spring), in cocopeat and rockwool substrates under shaded and unshaded greenhouse conditions. Bandita $F_{1}$ tomato variety was used as genetic material. In the study, fruit height and diameter $(\mathrm{mm})$, shape index, skin and flesh color (L, a, b, hue ${ }^{\mathrm{o}}$ and chroma*), titratable acidity (TA), total soluble solid contents (\%TSS), flesh firmness, EC and $\mathrm{pH}$ of fruit juice have been determined as quality parameter. As a result of the research; quality parameter of Bandita $F_{1}$ tomato cultivar grown in soilless culture were found to vary between $16.42-26.22{ }^{\circ} \mathrm{C}$ temperature and $96.1-455.93 \mu \mathrm{mol} \mathrm{m}^{-2} \mathrm{~s}^{-1}$ light intensity depending on the substrates. The highest average fruit height $(52.02 \mathrm{~mm})$, fruit diameter $(62.12 \mathrm{~mm})$ and fruit shape index (0.83) were obtained at the spring term of 2015 in all applications. The effects of cocopeat substrate on fruit skin color $\left(L, a, b\right.$, hue ${ }^{\circ}$ and chroma*) were found to be positive. In the study, the highest TSS $(5.66 \%)$ in tomato fruit observed from $24.60{ }^{\circ} \mathrm{C}$ temperature and $432.67 \mu \mathrm{mol} \mathrm{m}^{-}$ ${ }^{2} \mathrm{~s}^{-1}$ light intensity aplications. TSS\% value of tomato fruit increased in with increasing temperature and
}

Anahtar Sözcükler: Domates Iş1k Kalite Ortam Örtüaltı Sicaklık Keywords: Tomato Light Quality Substrate Greenhouse Temperature 
light intensity. The highest TA values $(0.44 \%)$ of tomato obtained from $16.42{ }^{\circ} \mathrm{C}$ temperature and 96.10 $\mu \mathrm{mol} \mathrm{m} \mathrm{m}^{-2}$ light intensity applications, and it increased by decreasing light. According to the whole quality parematers of tomatoes grown in soilless culture, fruit height, diameter and shape index, fruit juice, EC and $\mathrm{pH}$ values effected positivelly by high light (432.67-455.93 $\mu \mathrm{mol} \mathrm{m} \mathrm{m}^{-2} \mathrm{~s}^{-1}$ ) and high temperature $\left(24.60-26.22^{\circ} \mathrm{C}\right)$. In addition, it was determined that the cocopeat substrate was prominent the cultivation medium in soilless agriculture.

(C) OMU ANAJAS 2019

Bu araştırma, “Serada Topraksız Salkım Domates Yetiştiriciliğinde Büyüme, Gelişme ve Verim Üzerine Işık ve Sıcaklığın Kantitatif Etkilerinin Modellenmesi"' isimli doktora tez çalışmasından üretilmiştir.

\section{Giriş}

Domates, insan beslenmesinde yaygın olarak kullanılan, farklı şekillerde kullanım alanlarına sahip olan, vitamin ve mineral bakımından zengin önemli sebze türlerinden biridir. Dünya domates üretimi, 182.301.395 tondur (FAO, 2017). Domates Antarktika kıtası hariç, dünyanın neredeyse hemen hemen her yerinde en fazla üretimi yapılan sebzelerin başında gelmektedir. Türkiye, 12.150 .000 ton domates üretimiyle Dünya'da 4. sirada yer alan önemli üretici ülkelerden biridir. Dünya domates üretiminin yaklaşı \%7'lik kısmını ülkemiz karşılamaktadır. Ayrıca, domates üretiminin yaklaşık \%32'si (3.888.555 ton), örtüaltı sebze yetiştiriciliği ile gerçekleştirilmektedir (TÜIK, 2018). Son yıllarda ülkemizde topraksız tarım tekniklerinin örtüaltı üretiminde yoğun olarak kullanılması ve jeotermal kaynakların sera 1sıtmasında, topraksız tarıma entegre olması ile özellikle ekolojik olarak uygun olmayan bölgelerde dahi y1l boyunca üretim yapılabildiğinden örtüaltı domates yetiştiriciliği, yüksek verim ve kaliteli ürün düzeyinde önemli bir ivme kazanmıştır.

Topraksız tarım genel olarak, durgun veya akan besin eriyiklerinde veya besin eriyikleri ile beslenen katı ortamlarda bitkilerin yetiştirilmesi olarak tanımlanmaktadır (Güneş ve ark., 2012). Bu yetiştiricilik sistemi, bitki yaşamı için gerekli olan su ve besin elementlerinin kök ortamına gereken miktarlarda verilmesi esasına dayalıdır (Gül, 2008). Hızla artan dünya nüfusuna karşın yetersiz tarım alanı ve iklim faktörleri nedeniyle, dünya genelinde topraksız kültür kullanma eğiliminde bir artı̧̧ gözlenmektedir (Pardossi ve ark., 2011). Özellikle seracılığın yaygın olduğu alanlarda birçok sebze türünün yetiştiriciliğinde yaygın olarak katı ortam kültürü kullanılmaktadır (Nichols, 2002; Güneş ve ark., 2012). Bunun en önemli nedenleri; bu sistemin daha ucuz bir başlangıç yatırımına ihtiyaç duyması ve kök bölgesinin etrafinda tampon görevi yapan bir ortam oluşturması olarak açıklanabilir (Leonardi, 2004; Gül, 2008). Avrupa'da topraksız tarım yöntemiyle yapılan domates yetiştiriciliğinde substrat olarak en fazla, kayayünü ve Hindistan cevizi lifi kullanılmaktadır (Peet ve Heuvelink, 2005). Türkiye'de ise en çok kullanılan topraksız tarım büyüme ortamı Hindistan cevizi lifi, kayayünü ve perlit şeklinde sıralanabilir (Toprak ve Gül, 2013). Birçok araştırıcı, Hindistan cevizi lifinin domateste verim artışı ve kaliteli ürün eldesinde yararlı etkilerinin olduğunu bildirmişlerdir (Prasad ve ark., 2012; Kılıç, 2014;
Dönmez, 2015; Özkaplan, 2018).

Kaliteli ürün tüketici tarafından değer verilen özelliklerin bir arada olma şekli olarak ifade edilmektedir (Balkaya ve Özcan, 1997). Taze olarak tüketilen domateslerde meyve kalite özellikleri, genel olarak renk, şekil, irilik, sertlik, kuru madde, besin içeriği ve tat gibi parametrelerden oluşmaktadır. Her ne kadar tüketiciler tarafından domates meyvelerinde aranılan kalite unsurlarının başında; meyve görünümü gelse de kalite kavramı içerisinde toplam suda çözünür kuru madde miktarı, titre edilebilir asitlik, meyve suyu EC ve pH içeriği gibi kriterlerde dikkate alınmaktadır (Dorais ve ark., 2001). Meyvede görsel renk oluşumu; rengin $\mathrm{L}$, $\mathrm{a}$ ve $\mathrm{b}$ değerlerinin üç boyutlu bir düzlemde kesişmesiyle meydana gelmektedir. Ancak, gerçek renk değerlerinin yorumlanmasında çoğu zaman bu parametreler tek başına yeterli değildir. Bu nedenle, bu renk parametrelerinin kullanılarak chroma* ve hue ${ }^{o}$ değerlerinin hesaplanması oldukça önemlidir (Karaağaç, 2013).

Örtüaltı sebze yetiştiriciliğinde iklimsel parametreler ile yetiştirilecek bitkiler arasındaki ilişkilerin biliniyor olması yetiştiricilikte optimum büyüme ve gelişme ile yüksek verim potansiyeli açısından büyük bir önem taşımaktadır (Özkaplan, 2018). Domates yetiştiriciliğinin yapıldığ seralarda; dikimden, son hasada kadar olan dönem içerisinde, en uygun çevre koşullarının sağlanması ile ürünün, verimlilik ve meyve kalite unsurları artırılabilir (Kandemir ve ark., 2016). Özellikle sıcaklık ve ışık bitkide; fotosentez, solunum, net asimilasyon ve transpirasyon gibi fizyolojik olayların meydana gelmesinde ve bu olaylarla ilgili olarak bitkide büyüme ve gelişmeyi yönlendiren enzimlerin, hormonların ve renk pigmentlerinin oluşumunda önemli rol oynamaktadır (Uzun ve Demir, 1996). Yetiştiricilikte 1 şı ve sıcaklık arasındaki denge net asimilasyon artışı ve kuru madde üretiminin kontrolünde oldukça önemli bir etkiye sahiptir (Uzun, 2000). Sicaklık ve 1şık yoğunluğu meyvenin kalite özellikleri üzerine görünüş, sertlik, tekstür, kuru madde ve duyusal özellikleri bakımından doğrudan etkilidir. Bitki üzerine doğrudan gelen 1şı̆̆ın özellikle 1 şık miktarının fazla olduğu yaz aylarında meyvede şekil bozukluklarına neden olmaktadır. Ani sicaklık değişimleri veya gece gündüz arasındaki sıcaklık farkının fazla olması ise meyvede çatlamayı artırmaktadır (Dorais ve ark., 2001).

Başarılı bir yetiştiricilik için erkencilik ve yüksek verimin yanısıra ürün kalitesini de artırmaya yönelik çalışmalar oldukça önemlidir. Son yıllarda tüketicilerin 
sağlıklı ve kaliteli ürünlere olan taleplerindeki artış; araştırıcıların ürün kalitesine olan ilgilerini arttırmış çalışmalarını bu yönde yoğunlaştırmışlardır (Demirsoy, 2016; Karaağaç ve ark., 2018). Topraksız tarım domates yetiştiriciliğinde meyve kalitesi üzerine yetiştirme ortamlarının etkileri ile ilgili çok sayıda çalışma yürütülmüştür (Fandi ve ark., 2007; Borji ve ark., 2010; Sezen ve ark., 2010; Toprak ve Gül 2013; K1lıç, 2014; Dönmez, 2015). Ancak ülkemizde sıcaklık ve 1 şı koşullarının domateste meyve kalitesi üzerine etkilerinin belirlenmesine yönelik çalışma sayısı (Tüzel ve ark., 2009; Geboloğlu ve Yıldız, 2013; Demirsoy, 2016; Özkaplan, 2018) oldukça azdır. Bu konuda bilimsel çalışmaların sayısının artırılması büyük önem taşımaktadır. Bu çalışma ile Hindistan cevizi lifi ve kayayünü substratlarında yetiştirilen Bandita $F_{1}$ salkım domates çeşidinin meyve kalite unsurları üzerine farklı sıcaklık ve 1şık koşullarının etkilerinin ayrıntılı olarak tespit edilmesi ve ürün kalitesi açısından en uygun substratın belirlenmesi amaçlanmıştır.

\section{Materyal ve Yöntem}

\subsection{Materyal}

$\mathrm{Bu}$ çalışma, Ondokuz Mayıs Üniversitesi Ziraat Fakültesi'ne ait Araştırma Uygulama ve Sera Sitesinde, 2014-2015 yıllarında cam serada yürütülmüştür. Çalışmada, Bandita $F_{1}$ domates çeşidi kullanılmıştır. Mevcut doğal ışı, sıcaklık ve fotoperiyotta varyasyon oluşturulmasi amaciyla, gölgeleme etkisi $\% 55$, enerji tasarrufu \%58 oranında ve 1şık geçirgenliği \%45 olan akrilik, alüminyum, yüksek yoğunluklu polietilen (PEHD) dokuma özelliğine sahip gölgeleme ve enerji perdesi kullanılmıştır.

\subsection{Yöntem}

Araştımada, açık sistem topraksız tarım yetiştirme tekniğine uygun niteliklere sahip cam serada fideler; 4-5 gerçek yapraklı dönemde, Hindistan cevizi lifi ve hazır kayayünü yetiştirme torbalarına, her bir torbaya 3 adet fide olacak şekilde $30 \mathrm{~cm}$ aralıklar ile açılan küçük deliklere ( 2.2 bitki $\left.\mathrm{m}^{-2}\right)$ dikilmiş̧ir. Çalışmada; 2014 yılı ilkbahar döneminde domates fidesi dikimleri tüm uygulamalarda 03.04.2014 tarihinde (I. Dönem), 2014 yılı sonbahar yetiştiriciliğinde 29.08.2014 (II. Dönem) ve 2015 yll ilkbahar döneminde (III. Dönem) ise 05.03.2015 tarihinde dikilmiştir. Üç farklı dikim zamanı kullanılarak doğal 1şık, sıcaklık ve fotoperiyotta varyasyon oluşturulmuştur. Her bir dikim döneminde hem Hindistan cevizi lifi ve hem de kayayünü yetiştirme ortamlarına dikilen 30 domates fidesi, \%100 doğal ışı altında ve diğer 30 bitki ise gölgeleme materyali altında olacak şekilde iki farklı ekolojik çevrede yetiştirilmiştir. Her bir yetiştirme dönemi için iki farklı yetiştirme ortamında iki ayrı uygulama için toplam 120 domates bitkisi kullanılmıştır. Çalışmada dikimden bir gün önce, ortam doygun hale gelinceye kadar besin çözeltisiyle sulanmıştır. Bitkiler için gerekli olan su ve besin çözeltisinin bitki kök bölgesine dă̆ıtımı, damlama sulama sistemi yardımıyla sağlanmıştır. Çalışmada, kullanılan besin eriyiği, domates bitkilerinin ihtiyaç duyduğu besin maddelerinin sulama suyuna ilave edilmesiyle, komple besin eriyiği şeklinde modifiye edilmiş "Hoagland besin çözeltisi" ile sağlanmıştır (Çizelge 1).

Çizelge 1. Serada bitkilere uygulanan besin çözeltisinin kimyasal içerikleri

\begin{tabular}{ccc}
\hline Besin Elementi & Kullanilan Miktar $\left(\mathrm{mg} \mathrm{L}^{-1}\right)$ & Kullanilan Kimyasal Maddeler \\
\hline $\mathbf{N}$ & 242 & $\mathrm{NH}_{4} \mathrm{NO}_{3}$ \\
$\mathrm{P}$ & $31-54^{\circ}$ & $\mathrm{KH}_{2} \mathrm{PO}_{4}$ \\
$\mathrm{~K}$ & $234-263^{\circ}$ & $\mathrm{KNO}_{3}$ \\
$\mathrm{Ca}$ & 160 & $\mathrm{Ca}\left(\mathrm{NO}_{3}\right)_{2} .4 \mathrm{H}_{2} \mathrm{O}$ \\
$\mathrm{Mg}$ & 48 & $\mathrm{MgSO}_{4} .7 \mathrm{H}_{2} \mathrm{O}$ \\
$\mathrm{Fe}$ & 2.5 & $\mathrm{Fe} \mathrm{EDDHA}$ \\
$\mathrm{Mn}$ & 0.5 & $\mathrm{MnSO}_{2} . \mathrm{H}_{2} \mathrm{O}$ \\
$\mathrm{Zn}$ & 0.5 & $\mathrm{ZnSO}_{4} .7 \mathrm{H}_{2} \mathrm{O}$ \\
$\mathrm{Cu}$ & 0.02 & $\mathrm{CuSO}_{4} .5 \mathrm{H}_{2} \mathrm{O}$ \\
$\mathrm{B}$ & 0.05 & $\mathrm{H}_{3} \mathrm{BO}_{3}$ \\
$\mathrm{Mo}$ & 0.01 & $\left(\mathrm{NH}_{4}\right)_{6} \mathrm{Mo}_{7} \mathrm{O}_{24} .4 \mathrm{H}_{2} \mathrm{O}$ \\
\hline
\end{tabular}

Meyve tutumundan sonraki periyotta uygulanan besin çözeltisi miktar

Araştırmada domates yetiştiriciliğinde uygulanan besin çözeltisi, fide dikiminden meyve tutumuna kadar ve meyve tutumundan hasata kadar olmak üzere iki farklı konsantrasyonda hazırlanmıştır. Bitkilere besin çözeltisi uygulamadan önce besin çözeltisinde $\mathrm{pH}$ ve EC ölçümü yapılmış, uygulanan nitrik asit ilavesi ile $\mathrm{pH}$ değerinin 6.0-6.5 ve EC değerinin ise $2.0-2.5 \mathrm{ds} \mathrm{m}^{-1}$ sınırları içinde kalması sağlanmıştır. Sera içi hava sıcaklığ 1 ve fotosentetik aktif radyasyon değerleri bilgisayar yardımı ile programlanabilen Onset hobo datalogger ve Quantum par sensörleri ile ölçülerek kaydedilmiştir (Çizelge 2). 
Çizelge 2. Farklı yetiştirme dönemlerine ait ortalama sıcaklık ve 1şık değerleri

\begin{tabular}{|c|c|c|}
\hline & Sicaklik & Iş1k \\
\hline \multicolumn{3}{|l|}{2014 y1lı ilkbahar (I. Dönem) } \\
\hline Hindistan cevizi lifi & $26.22^{\circ} \mathrm{C}$ & $455.93 \mu \mathrm{mol} \mathrm{m}^{-2} \mathrm{~s}^{-1}$ \\
\hline Hindistan cevizi lifi (\%50 gölgeli) & $23.96^{\circ} \mathrm{C}$ & $264.54 \mu \mathrm{mol} \mathrm{m}^{-2} \mathrm{~s}^{-1}$ \\
\hline Kayayünü & $26.22{ }^{\circ} \mathrm{C}$ & $455.93 \mu \mathrm{mol} \mathrm{m} \mathrm{s}^{-2}$ \\
\hline Kayayünü (\%50 gölgeli) & $23.96^{\circ} \mathrm{C}$ & $264.54 \mu \mathrm{mol} \mathrm{m} \mathrm{s}^{-2}$ \\
\hline \multicolumn{3}{|l|}{2015 yılı ilkbahar (III. Dönem) } \\
\hline Hindistan cevizi lifi & $24.60^{\circ} \mathrm{C}$ & $432.67 \mu \mathrm{mol} \mathrm{m} \mathrm{m}^{-2}$ \\
\hline Hindistan cevizi lifi (\%50 gölgeli) & $22.71{ }^{\circ} \mathrm{C}$ & $182.31 \mu \mathrm{mol} \mathrm{m} \mathrm{s}^{-2}$ \\
\hline Kayayünü & $24.60{ }^{\circ} \mathrm{C}$ & $432.67 \mu \mathrm{mol} \mathrm{m}^{-2} \mathrm{~s}^{-1}$ \\
\hline Kayayünü (\%50 gölgeli) & $22.71^{\circ} \mathrm{C}$ & $182.31 \mu \mathrm{mol} \mathrm{m} \mathrm{s}^{-2}$ \\
\hline \multicolumn{3}{|l|}{2014 yılı sonbahar (II. Dönem) } \\
\hline Hindistan cevizi lifi & $18.14^{\circ} \mathrm{C}$ & $223.46 \mu \mathrm{mol} \mathrm{m} \mathrm{s}^{-2}$ \\
\hline Hindistan cevizi lifi (\%50 gölgeli) & $16.42^{\circ} \mathrm{C}$ & $96.10 \mu \mathrm{mol} \mathrm{m} \mathrm{s}^{-2}$ \\
\hline Kayayünü & $18.14^{\circ} \mathrm{C}$ & $223.46 \mu \mathrm{mol} \mathrm{m}^{-2} \mathrm{~s}^{-1}$ \\
\hline Kayayünü (\%50 gölgeli) & $16.42^{\circ} \mathrm{C}$ & $96.10 \mu \mathrm{mol} \mathrm{m} \mathrm{s}^{-2}$ \\
\hline
\end{tabular}

Araştırmada aşağıda ayrıntılı olarak belirtilen meyve kalite özellikleri incelenmiştir.

a) Meyve boyu ve meyve çap $1(\mathrm{~mm})$ : Meyvenin sap çukuru ve çiçek çukuru arasındaki mesafe meyve boyu, meyve sapına dik ve en geniş nokta (ekvator) ise meyve çapı olarak dijital kumpas ile ölçülmüştür.

b) Meyve şekil indeksi: Meyve boyu ve meyve çapı ortalamalarının oranlanması ile meyve şekil indeksi değerleri belirlenmiştir.

c) Meyve kabuk rengi ve meyve et renginin belirlenmesi: Her uygulama için hasat olumundaki ölçüm ve gözlem bitkilerinden rastgele seçilen meyvelerde, kabuk ve et rengi Minolta CR-410 tristimulus dijital renk ölçüm aleti kullanılarak belirlenmiştir. Renk ölçümü, CIE L a*b* renk sınıflandırma sistemine göre yapılmıştır (Demirsoy, 2016). Kabuk dış rengi, meyvede 3 farklı kısımda okunmuştur. Meyve kabuk renk değerleri (L, a, b) ölçülmüştür. Elde edilen bu değerlerden kroma ve hue (b/a) açısı değerleri Mcguire (1992)'e göre hesaplanmıştır.

d) Meyve eti sertliği $\left(\mathrm{kg} \mathrm{m}^{-2}\right)$ : Her bir uygulama için hasat olumundaki ölçüm ve gözlem bitkilerinden elde edilen meyvelerde TR marka FT-327 model el penetrometresine $8 \mathrm{~mm}$ 'lik uç takılarak meyve eti sertliği değerleri $\mathrm{kg} / \mathrm{m}^{2}$ olarak belirlenmiştir.

e) Suda çözünebilir kuru madde miktarı (\%): Hasat olumundaki meyvelerden alınan meyve suyu örnekleri, Atogo marka MASTER-M model el refraktometresi ile ölçülmüş ve suda çözünür kuru madde miktarı değerleri yüzde şeklinde okunmuştur.

f) Titre edilebilir asitlik (TA), meyve suyunda $\mathrm{pH}$ ve EC miktarının belirlenmesi: Domates meyvelerinden alınan meyve suyu örneklerinde $\mathrm{pH}$ ve $\mathrm{EC}$ ölçümleri dijital $\mathrm{pH}$ metre ve EC ölçer ile yapılmıştır. Titre edilebilir asitlik ölçümleri ise Cemeroğlu (2007)'ye göre yapılmıştır.

\subsection{Verilerin değerlendirilmesi}

Araştırma, faktöriyel deneme desenine göre her uygulamada 3 tekerrür olacak şekilde kurulmuştur. Elde edilen sayısal verilere varyans analizi uygulanmış ve SAS-JMP 5.01 istatistiktik paket programında analiz edilmiştir. Deneme hatasının oranını gösteren doğruluk katsayıları (CV) hesaplanmıştır.

\section{Bulgular ve Tartışma}

Dünyada ve ülkemizde sebze kalite standartları daha çok ürünün dış görünüşüne göre yapılmaktadır. Özellikle sebzelerin, tüketiciler tarafindan kabul edilebilirliğini etkileyen çok sayıda kalite kriteri bulunmaktadır (Karaağaç ve ark., 2018). Sebzelerde kalite özellikleri; irilik, şekil, renk, dış kusur gibi görünüş özellikleri; tekstür, tat ve aroma gibi organoleptik özellikler ve karotenoidler, vitaminler, fenolik bileşikler ve mineraller gibi fonksiyonel özellikler olmak üzere dört ana gruba ayrılmaktadır (Leonardi ve ark., 2017).

Araştırma sonucunda, ortalama meyve boyu değerleri yönünden, uygulamalar arasında önemli düzeyde farklılıklar olduğu saptanmıştır (Çizelge 3). En yüksek meyve boyu değeri, $52.02 \mathrm{~mm}$ ile 2015 yılı ilkbahar dikim döneminden elde edilmiştir. Substratlar arasında, meyve boyu yönünden istatistiksel olarak önemli düzeyde farklılıklar olduğu saptanmıştır. Hindistan cevizi lifi yetiştirme ortamında yetiştirilen domateslerde, ortalama meyve boyunun $(48.49 \mathrm{~mm})$, kayayünü yetiştirme ortamına $(47.74 \mathrm{~mm})$ göre daha yüksek olduğu belirlenmiştir. Hindistan cevizi lifi ve kayayünü substratlarında yetiştirilen meyveler arasında meyve çap1 değerleri yönünden incelendiğinde, istatistiksel olarak önemli düzeyde bir farklılık bulunmamıştır (Çizelge 3). 
Çalışmada, dikim dönemleri, dönemxışık interaksiyonları arasında ortalama meyve çapı yönünden $\mathrm{P}<0.05$ 'e göre önemli derecede farklılıklar olduğu saptanmıştır. Ortalama meyve çapı değerleri, $57.01 \mathrm{~mm}$
- $62.12 \mathrm{~mm}$ arasında değişim göstermiştir. Çalışmada, artan 1şık yoğunluğu ve artan sıcaklık değerlerinin meyve boyutlarında artışa neden olmuştur.

Çizelge 3. Farklı 1şık ve sıcaklık şartlarında değişik ortamlarda yetiştirilen salkım domateslerde meyve boyutlarının (boy, çap, indeks) değişimleri (*P<0.05,CV:\%2.1) ${ }^{\mathbf{a}},\left({ }^{*} \mathrm{P}<0.05, \mathrm{CV}: \% 1.9\right)^{\mathbf{b}},(* \mathrm{P}<0.05, \mathrm{CV}: 2.0)^{\mathbf{c}}$

\begin{tabular}{|c|c|c|c|c|c|c|c|c|c|c|}
\hline \multicolumn{11}{|c|}{ Meyve boyu $(\mathrm{mm})^{\text {a }}$} \\
\hline \multirow{2}{*}{ Substrat } & \multicolumn{3}{|c|}{ I. Dönem } & \multicolumn{3}{|c|}{ II. Dönem } & \multicolumn{3}{|c|}{ III. Dönem } & \multirow[b]{2}{*}{ Ort.* } \\
\hline & Iş1k & Gölge & Ort.* & Iş1k & Gölge & Ort.* & Iş1k & Gölge & Ort.* & \\
\hline HCL & 48.62 & 47.72 & $48.17 \mathrm{c}$ & 43.91 & 42.0 & $42,95 \mathrm{e}$ & 54.24 & 54.42 & $54.33 a$ & $48.49 \mathrm{a}$ \\
\hline KY & 45.98 & 48.11 & $47.04 \mathrm{~cd}$ & 48.14 & 44.83 & $46,49 d$ & 49.28 & 50.13 & $49.71 b$ & $47.74 b$ \\
\hline Ort.* & $47.30 \mathrm{~b}$ & $47.91 \mathrm{~b}$ & & $46.03 \mathrm{c}$ & $43.04 d$ & & $51.76 \mathrm{a}$ & $52.28 \mathrm{a}$ & & \\
\hline Dönem* & & $47.61 \mathrm{~b}$ & & & $44.72 \mathrm{c}$ & & & $52.02 \mathrm{a}$ & & \\
\hline \multicolumn{11}{|c|}{ Meyve çapı $(\mathrm{mm})^{\mathrm{b}}$} \\
\hline \multirow{2}{*}{ Substrat } & \multicolumn{3}{|c|}{ I. Dönem } & \multicolumn{3}{|c|}{ II. Dönem } & \multicolumn{3}{|c|}{ III. Dönem } & \\
\hline & Işı1k* & Gölge* & Ort.* & Iş1k* & Gölge* & Ort.* & Iş1k* & Gölge* & Ort.* & Ort. \\
\hline HCL & $58.7 \mathrm{de}$ & $57.4 \mathrm{ef}$ & $58.1 \mathrm{c}$ & $53.91 \mathrm{~g}$ & $55.66 \mathrm{fg}$ & $54.78 \mathrm{e}$ & $63.90 \mathrm{a}$ & $63.26 \mathrm{ab}$ & $63.58 \mathrm{a}$ & 58.83 \\
\hline KY & $55.9 \mathrm{f}$ & $57.2 \mathrm{ef}$ & $56.5 \mathrm{~d}$ & $60.14 \mathrm{~cd}$ & $58.35 \mathrm{de}$ & $59.25 \mathrm{c}$ & $59.72 \mathrm{~cd}$ & $61.59 b c$ & $60.66 b$ & 58.82 \\
\hline Ort. & 57.35 & 57.32 & & 57.02 & 57.01 & & 61.81 & 62.43 & & \\
\hline Dönem* & & $57.33 \mathrm{~b}$ & & & $57.01 \mathrm{~b}$ & & & $62.12 \mathrm{a}$ & & \\
\hline \multicolumn{11}{|c|}{ Meyve şekil indeksi ${ }^{c}$} \\
\hline \multirow{2}{*}{ Substrat } & \multicolumn{3}{|c|}{ I. Dönem } & \multicolumn{3}{|c|}{ II. Dönem } & \multicolumn{3}{|c|}{ III. Dönem } & \\
\hline & Işık & Gölge & Ort.* & Iş1k & Gölge & Ort.* & Iş1k & Gölge & Ort.* & Ort. \\
\hline HCL & 0.82 & 0.82 & $0.82 b$ & 0.81 & 0.75 & $0.78 \mathrm{c}$ & 0.84 & 0.85 & $0.85 \mathrm{a}$ & 0.81 \\
\hline KY & 0.82 & 0.83 & $0.82 b$ & 0.79 & 0.76 & $0.78 \mathrm{c}$ & 0.82 & 0.81 & $0.81 b$ & 0.80 \\
\hline Ort.* & $0.82 \mathrm{ab}$ & $0.83 \mathrm{a}$ & & $0.80 \mathrm{~b}$ & $0.75 \mathrm{c}$ & & $0.83 \mathrm{a}$ & $0.83 a$ & & \\
\hline Dönem* & & $0.82 \mathrm{a}$ & & & $0.78 b$ & & & $0.83 \mathrm{a}$ & & \\
\hline
\end{tabular}

Düşük sıcaklık değerlerinin meyve gelişimini yavaşlattığı (Nothmann, 1986) ve artan günlük $1 s ̧ 1 k$ yoğunluğunun ise domateslerde meyve gelişimini pozitif yönde etkilediği birçok araştırıcı tarafından bildirilmiştir (Cockshull ve ark., 1992; Pearson, 1992; De Koning, 1994 ve Uzun, 2007).

Çalışmada meyve şekil indeksi değeri üzerine; dikim dönemi $(\mathrm{P}<0.05)$ ve gölge uygulamalarının etkisinin $(\mathrm{P}<0.05)$ ve bu iki faktör arasındaki interaksiyon sonuçlarının önemli düzeyde farklılık gösterdiği bulunmuştur (Çizelge 3). Gölge uygulamalarına bağlı olarak en yüksek meyve şekil indeksi (0.83) değeri, 2014 yll ilkbahar ve 2015 yll ilkbahar yetiştirme dönemlerinde belirlenmiştir. Yetiştirme ortamları bakımından karşılaştırıldığında ise en yüksek meyve şekil indeksi değeri, kayayünü yetiştirme ortamında yetiştirilen meyvelerde (0.81) saptanmıştır. Çalışmada, artan sıcaklık ve 1şık şiddetinin meyve şekil indeksi değerlerini pozitif yönde etkilediği tespit edilmiştir. Benzer sonuç, Demirsoy (2016) tarafindan da artan $1 s ̧ 1 \mathrm{k}$ şiddetinin meyve şekil indeksini artırdığ 1 şeklinde bildirilmiştir.

Domates meyvelerinde, meyve albenisini etkileyen en önemli kalite parametrelerden biri de meyve rengidir (Matas ve ark., 2009). Meyvede renk oluşumu; genotip sıcaklık ve bitki besleme gibi çevresel faktörlere bağlı olarak değişkenlik göstermektedir. (Lopez Camelo ve Gomez, 2004). Domateslerde meyve renginde parlaklığı, L değeri temsil eder (Mcguire, 1992). Hasat sonucunda elde edilen ortalama $\mathrm{L}$ değerleri, ortam ve dönemxışık interaksiyonları arasında önemli seviyede farklılıklar olduğunu göstermiştir (Çizelge 4). Substratlara bağlı olarak, meyve rengine ait $\mathrm{L}$ değerleri incelendiğinde en yüksek değer 52.11 ile Hindistan cevizi lifinden elde edilmiştir. Bu konuda yapılan araştırma sonuçları incelendiğinde, elde edilen sonuçların birbirinden farklılık gösterdiği görülmüştür. Toprak ve Gül (2013) en parlak domates meyvelerini Hindistan cevizi lifi ortamında olduğunu bildirirken; Dönmez (2015) kayayünü yetiştirme ortamında daha parlak meyvelerin elde edildiğini bildirmiştir. Çalışmada en parlak meyveler, yüksek sıcaklık ve yüksek 1şık şartlarında yetiştirilen bitkilerde saptanmıştır. Renk ölçümünde incelenen a ve b değeri, $\mathrm{L}$ değerine dik bir renk düzleminde domates meyve rengini oluşturur. Young ve ark. (1993), domates meyvelerinde a değerinin, meyvede olgunluğu ifade ettiğini ve bu değer ile meyvenin fizyolojik yaşının da tespit edilebildiğini bildirmiş̧lerdir. Araştırmada a değerlerinin dönem, dönemxışık, dönemxortam ve dönemxortamxışı interaksiyonları arasında istatistiksel olarak önemli düzeyde faklılıklar gösterdiği 
saptanmıştır (Çizelge 4). Hasat edilen meyveler, a değerleri yönünden incelendiğinde; en yüksek değer 25.4 ile 2014 yılı ilkbahar döneminde elde edilmiştir. Araştırma sonuçlarına benzer olarak; Tüzel ve ark. (2009) domates meyvelerinde a değerini 13.2-21.0 ve
Demirtaş ve ark. (2012) ise 17.10-20.10 arasında değişim gösterdiğini bildirmişlerdir. Substratlar bazında değerlendirildiğinde; ortalama meyve rengi $b$ değerinin en yüksek 35.1 ile Hindistan cevizi lifi ortamında olduğu tespit edilmiştir (Çizelge 4).

Çizelge 4. Farklı ışık ve sıcaklık şartlarında değişik ortamlarda yetiştirilen salkım domateslerde meyve kabuk rengi $\mathrm{L}, \mathrm{a}, \mathrm{b}$, hue $^{\mathrm{o}}$, chroma* değerlerinin değişimi $\left({ }^{*} \mathrm{P}<0.05, \mathrm{CV}: \% 2.3\right)^{\mathbf{a}},\left({ }^{*} \mathrm{P}<0.05, \mathrm{CV}: \% 8.3\right)^{\mathbf{b}},\left({ }^{*} \mathrm{P}<0.05\right.$, $\mathrm{CV}: \% 6.3)^{\mathbf{c}},(* \mathrm{P}<0.05, \mathrm{CV}: \% 2.6)^{\mathbf{d}},(* \mathrm{P}<0.05, \mathrm{CV}: \% 6.7)^{\mathbf{e}}$

\begin{tabular}{|c|c|c|c|c|c|c|c|c|c|c|}
\hline \multicolumn{11}{|c|}{ Meyve kabuk rengi L değeri ${ }^{a}$} \\
\hline \multirow{2}{*}{ Substrat } & \multicolumn{3}{|c|}{ I. Dönem } & \multicolumn{3}{|c|}{ II. Dönem } & \multicolumn{3}{|c|}{ III. Dönem } & \multirow[b]{2}{*}{ Ort.* } \\
\hline & Işık & Gölge & Ort. & Iş1k & Gölge & Ort. & Iş1k & Gölge & Ort. & \\
\hline HCL & 52.28 & 51.32 & 51.80 & 53.58 & 50.23 & 51.91 & 53.55 & 51.69 & 52.62 & $52.11 \mathrm{a}$ \\
\hline KY & 52.80 & 49.37 & 51.08 & 54.04 & 48.18 & 51.11 & 51.64 & 49.51 & 50.58 & $50.92 b$ \\
\hline Ort.* & $52.54 \mathrm{a}$ & $50.34 \mathrm{~b}$ & & $53.81 \mathrm{a}$ & $49.21 \mathrm{~b}$ & & $52.60 \mathrm{a}$ & $50.60 \mathrm{~b}$ & & \\
\hline Dönem & \multicolumn{2}{|r|}{51.44} & & \multicolumn{3}{|c|}{51.51} & \multicolumn{3}{|c|}{51.60} & \\
\hline \multicolumn{11}{|c|}{ Meyve kabuk rengi a değeri ${ }^{b}$} \\
\hline \multirow{2}{*}{ Substrat } & \multicolumn{3}{|c|}{ I. Dönem } & \multicolumn{3}{|c|}{$\begin{array}{l}\text { II. Dönem } \\
\end{array}$} & \multicolumn{3}{|c|}{ III. Dönem } & \\
\hline & Iş1k* & Gölge* & Ort.* & Iş1k* & Gölge* & Ort.* & Iş1k* & Gölge* & Ort.* & Ort. \\
\hline HCL & $22.4 \mathrm{abcd}$ & $23.4 \mathrm{ab}$ & $22.9 a$ & $19.9 \mathrm{~d}$ & $15.7 \mathrm{e}$ & $17.8 \mathrm{c}$ & $24.9 \mathrm{a}$ & $20.0 \mathrm{~cd}$ & $22.4 \mathrm{a}$ & 21.10 \\
\hline KY & $25.4 \mathrm{a}$ & 22.9abc & $24.1 \mathrm{a}$ & $21.5 \mathrm{bcd}$ & $16.0 \mathrm{e}$ & $18.8 \mathrm{bc}$ & $19.8 \mathrm{~d}$ & $20.6 \mathrm{bcd}$ & $20.2 b$ & 21.08 \\
\hline Ort* & $23.9 \mathrm{a}$ & $23.2 \mathrm{a}$ & & $20.78 b$ & $15.87 \mathrm{c}$ & & $22.3 \mathrm{ab}$ & $20.35 b$ & & \\
\hline Dönem* & \multicolumn{3}{|c|}{$23.58 \mathrm{a}$} & \multicolumn{3}{|c|}{$18.32 \mathrm{c}$} & \multicolumn{3}{|c|}{$21.36 \mathrm{~b}$} & \\
\hline \multicolumn{11}{|c|}{ Meyve kabuk rengi b değeri ${ }^{c}$} \\
\hline \multirow{2}{*}{ Substrat } & \multicolumn{3}{|c|}{ I. Dönem } & \multicolumn{3}{|c|}{ II. Dönem } & \multicolumn{3}{|c|}{ III. Dönem } & \\
\hline & Iş1k* & Gölge* & Ort.* & Iş1k* & Gölge* & Ort.* & Iş1k* & Gölge* & Ort.* & Ort. \\
\hline $\mathrm{HCL}$ & $30.9 \mathrm{bc}$ & $31.9 \mathrm{bc}$ & $31.4 \mathrm{a}$ & $26.5 \mathrm{e}$ & $22.0 \mathrm{f}$ & $24.2 \mathrm{c}$ & $35.1 \mathrm{a}$ & $26.2 \mathrm{e}$ & $30.9 \mathrm{a}$ & 28.89 \\
\hline KY & $32.5 \mathrm{ab}$ & $30.3 \mathrm{bcd}$ & $31.4 \mathrm{a}$ & $29.0 \mathrm{cde}$ & $21.5 f$ & $25.3 \mathrm{bc}$ & $26.9 \mathrm{e}$ & $27.3 \mathrm{de}$ & $27.1 \mathrm{~b}$ & 27.95 \\
\hline Ort* & $31.75 \mathrm{a}$ & $31.10 \mathrm{a}$ & & $27.79 b$ & $21.79 \mathrm{c}$ & & $31.01 \mathrm{a}$ & $27.11 \mathrm{~b}$ & & \\
\hline Dönem* & \multicolumn{3}{|c|}{$31.43 \mathrm{a}$} & \multicolumn{3}{|c|}{$24.79 \mathrm{c}$} & \multicolumn{3}{|c|}{$29.06 \mathrm{~b}$} & \\
\hline \multicolumn{11}{|c|}{ Meyve kabuk rengi $\mathrm{Hue}^{\mathrm{o}}$ açısı değeri ${ }^{\mathrm{d}}$} \\
\hline Substrot & & Dönem & & & Dönem & & & II. Dönen & & \\
\hline Nutsoliat & Işık & Gölge & Ort. & Iş1k & Gölge & Ort. & Iş1k & Gölge & Ort. & Ort. \\
\hline HCL & 54.01 & 53.66 & 53.83 & 53.06 & 54.53 & 53.79 & 54.59 & 53.35 & 53.97 & 53.87 \\
\hline KY & 52.02 & 52.86 & 52.44 & 53.48 & 53.36 & 53.42 & 53.63 & 52.87 & 53.25 & 53.03 \\
\hline Ort. & 53.02 & 53.26 & & 53.27 & 53.94 & & 54.11 & 53.11 & & \\
\hline Dönem & & 53.14 & & & 53.61 & & & 53.61 & & \\
\hline & & & & ve kabuk & ngi chro & değeri & & & & \\
\hline Substrot & & Dönem & & & . Dönem & & & II. Dönen & & \\
\hline Sübriat & Iş1k* & Gölge* & Ort.* & Iş1k* & Gölge* & Ort.* & Iş1k* & Gölge* & Ort.* & Ort. \\
\hline HCL & $38.2 \mathrm{bcd}$ & $39.6 a b c$ & $38.9 a$ & $33.2 \mathrm{e}$ & $27.0 \mathrm{f}$ & $30.1 \mathrm{c}$ & $43.0 \mathrm{a}$ & $33.5 \mathrm{e}$ & $38.2 \mathrm{a}$ & 35.78 \\
\hline KY & $41.3 \mathrm{ab}$ & $38.0 \mathrm{bcd}$ & $39.6 a$ & $36.2 \mathrm{cde}$ & $26.8 f$ & $31.5 \mathrm{bc}$ & $33.4 \mathrm{e}$ & $34.2 \mathrm{de}$ & $33.8 b$ & 35.02 \\
\hline Ort.* & $39.7 \mathrm{a}$ & $38.8 \mathrm{a}$ & & $34.7 \mathrm{~b}$ & $29.9 c$ & & $38.2 \mathrm{a}$ & $33.8 \mathrm{~b}$ & & \\
\hline Dönem* & & 39.30a & & & $30.84 \mathrm{c}$ & & & $36.07 \mathrm{~b}$ & & \\
\hline
\end{tabular}

Yetiştirme dönemlerine göre ortalama meyve rengi $b$ değerleri incelendiğinde; en düşük değer 24.79 ile 2014 y1lı sonbahar döneminde ve en yüksek değer ise 31.43 ile 2014 y1lı ilkbahar döneminde kayayünü yetiştirme ortamından elde edilmiştir. Tüzel ve ark. (2009) ve Demirtaş ve ark. (2012), domates meyvelerinde b değerinin sırasıyla; $22.2-28.3$ ve $18.32-20.28$ arasında değişim gösterdiğini bildirmişlerdir. Domateste meyve rengi hue ${ }^{0}$ renk açısı değerleri, rengin tonunu ifade etmektedir. Yetiştirme dönemleri arasında istatistiksel olarak $\mathrm{P}<0.05$ 'e göre önemli düzeyde bir farklılık olmakla birlikte, en fazla hue ${ }^{\circ}$ açısı değeri 54.59 değeri ile 2015 yll ilkbahar döneminde tespit edilmiştir (Çizelge 4). Kaya (2012), domateste en düşük hue açısı 
değerinin 29.6 ve en yüksek hue açısı değerinin ise 57.20 olduğunu bildirmiştir. Hue ${ }^{\circ}$ renk açısının düşük oluşu, kırmızı rengin daha iyi görünmesine neden olduğundan uygulamalar arasında en yoğun kırmızı meyveler, kayayünü substartlarında, yüksek 1 şı ve yüksek sıcaklık koşulları altında olduğu belirlenmiştir. Domates meyvelerinde meyve kabuk rengi, chroma* değerleri, rengin doygunluğunu ve canlılığını ifade eder (Radzevicius ve ark., 2009). Araştırma sonucunda tüm uygulamalar arasinda meyve kabuk rengi chroma değerlerinin $\mathrm{P}<0.05$ 'e göre önemli derecede farklılıklar gösterdiği saptanmıştır (Çizelge 4). En yüksek chroma değeri, 39.30 ile 2014 yllı ilkbahar döneminden elde edilmiştir. Çalışmada Hindistan cevizi lifi ve kayayünü yetiştirme ortamları arasında meyve rengi chroma değeri bakımından istatistiksel olarak önemli düzeyde bir farklılığın olmadığı, ancak 35.78 değeri ile Hindistan cevizi lifinin öne çıktığı bulunmuştur. Araştırmada azalan ışı şiddeti, domateslerde meyve rengi chroma değerini düşürmüştür. Sönmez ve Ellialtığlu (2014), düşük 1 şı yoğunluğunun düzensiz meyve renk oluşumuna neden olduğunu bildirmişlerdir. Hindistan cevizi lifinde yetiştirilen domateslerde; meyve et rengi L değerinin (48.76), kayayünü ortamına (47.76) göre daha fazla olduğu belirlenmiştir (Çizelge 5). Meyve et rengi verileri $\mathrm{a}$ ve $\mathrm{b}$ değerleri yönünden incelendiğinde; uygulamalar arasında önemli düzeylerde farklılıklar olduğu bulunmuştur (Çizelge 5).

Çizelge 5. Farklı 1şık ve sıcaklık şartlarında değişik ortamlarda yetiştirilen salkım domateslerde dikim dönemlerine göre meyve et rengi $\mathrm{L}, \mathrm{a}, \mathrm{b}$, hue ${ }^{\mathrm{o}}$, chroma* değerleri $(* \mathrm{P}<0.05, \mathrm{CV}: \% 6.8)^{\mathbf{a}},(* \mathrm{P}<0.05, \mathrm{CV}: \% 9.6)^{\mathbf{b}}$, $(* \mathrm{P}<0.05, \mathrm{CV}: \% 9.7)^{\mathbf{c}},(* \mathrm{P}<0.05, \mathrm{CV}: \% 9.7)^{\mathbf{d}},(* \mathrm{P}<0.05, \mathrm{CV}: \% 8.4)^{\mathbf{e}}$

\begin{tabular}{|c|c|c|c|c|c|c|c|c|c|c|}
\hline \multicolumn{11}{|c|}{ Meyve et rengi L değeri ${ }^{a}$} \\
\hline \multirow{2}{*}{ Ortam } & \multicolumn{3}{|c|}{ I. Dönem } & \multicolumn{3}{|c|}{ II. Dönem } & \multicolumn{3}{|c|}{ III. Dönem } & \multirow[b]{2}{*}{ Ort. } \\
\hline & Iş1k & Gölge & Ort. & Iş1k & Gölge & Ort. & Işı1k & Gölge & Ort. & \\
\hline HCL & 50.38 & 49.58 & 49.98 & 47.88 & 48.57 & 48.22 & 46.34 & 49.8 & 48.07 & 48.76 \\
\hline KY & 47.23 & 48.09 & 47.66 & 53.72 & 45.66 & 49.69 & 45.61 & 46.23 & 45.92 & 47.76 \\
\hline Ort. & 48.8 & 48.84 & & 50.8 & 47.11 & & 45.97 & 48.01 & & \\
\hline Dönem & & 48.82 & & & 48.96 & & & 46.99 & & \\
\hline \multicolumn{11}{|c|}{ Meyve et rengi a değeri ${ }^{b}$} \\
\hline \multirow{2}{*}{ Ortam } & \multicolumn{3}{|c|}{ I. Dönem } & \multicolumn{3}{|c|}{ II. Dönem } & \multicolumn{3}{|c|}{ III. Dönem } & \\
\hline & Iş1k* & Gölge* & Ort.* & Iş1k* & Gölge* & Ort.* & $\mathrm{Iş}_{\mathrm{1}} \mathrm{k}^{*}$ & Gölge* & Ort.* & Ort.* \\
\hline HCL & $11.6 \mathrm{de}$ & $12.8 \mathrm{cde}$ & $12.2 \mathrm{~cd}$ & $14.7 \mathrm{abc}$ & $11.7 \mathrm{de}$ & $13.2 \mathrm{bc}$ & $11.4 \mathrm{de}$ & $14.1 \mathrm{abc}$ & $12.7 \mathrm{~cd}$ & $12.7 \mathrm{~b}$ \\
\hline KY & $15.5 \mathrm{ab}$ & $13.4 \mathrm{bcd}$ & $14.4 \mathrm{ab}$ & $16.0 \mathrm{a}$ & $15.5 \mathrm{ab}$ & $15.7 \mathrm{a}$ & 11.8de & $11.2 \mathrm{e}$ & $11.5 \mathrm{~d}$ & $13.9 \mathrm{a}$ \\
\hline Ort* & $13.58 \mathrm{~b}$ & $13.13 \mathrm{bc}$ & & $15.37 \mathrm{a}$ & $13.61 \mathrm{~b}$ & & $11.64 \mathrm{c}$ & $12.67 \mathrm{bc}$ & & \\
\hline Dönem & & $13.36 \mathrm{~b}$ & & & $14.49 \mathrm{a}$ & & & $12.15 \mathrm{c}$ & & \\
\hline \multicolumn{11}{|c|}{ Meyve et rengi b değeri ${ }^{c}$} \\
\hline \multirow{2}{*}{ Ortam } & \multicolumn{3}{|c|}{ I. Dönem } & \multicolumn{3}{|c|}{$\begin{array}{l}\text { II. Dönem } \\
\end{array}$} & \multicolumn{3}{|c|}{ III. Dönem } & \\
\hline & Iş1k & Gölge & Ort. & Iş1k & Gölge & Ort. & Iş1k & Gölge & Ort. & Ort.* \\
\hline $\mathrm{HCL}$ & $19.07 \mathrm{~b}$ & $21.23 \mathrm{ab}$ & 20.15 & $19.19 b$ & $14.16 \mathrm{c}$ & 16.67 & $20.33 b$ & $20.08 b$ & 20.21 & $19.01 b$ \\
\hline KY & $23.90 \mathrm{a}$ & $19.12 b$ & 21.51 & $21.70 \mathrm{ab}$ & $20.0 b$ & 20.85 & $21.37 \mathrm{ab}$ & $20.81 \mathrm{ab}$ & 21.09 & $21.15 \mathrm{a}$ \\
\hline Ort. & 21.48 & 20.17 & & 20.44 & 17.08 & & 20.85 & 20.45 & & \\
\hline Dönem* & & $20.83 a$ & & & $18.76 \mathrm{~b}$ & & & $20.65 \mathrm{a}$ & & \\
\hline \multicolumn{11}{|c|}{ Meyve et rengi $\mathrm{Hue}^{\mathrm{o}}$ açısı değeri ${ }^{\mathrm{d}}$} \\
\hline \multirow{2}{*}{ Ortam } & \multicolumn{3}{|c|}{ I. Dönem } & \multicolumn{3}{|c|}{$\begin{array}{l}\text { II. Dönem } \\
\end{array}$} & \multicolumn{3}{|c|}{ III. Dönem } & \\
\hline & Iş1k & Gölge & Ort. & Iş1k & Gölge & Ort. & Iş1k & Gölge & Ort. & Ort. \\
\hline $\mathrm{HCL}$ & 58.57 & 58.86 & 58.71 & 52.50 & 50.39 & 51.45 & 60.55 & 54.95 & 57.75 & 55.97 \\
\hline KY & 56.91 & 55.08 & 56.00 & 53.60 & 52.21 & 52.90 & 60.54 & 60.43 & 60.49 & 56.46 \\
\hline Ort. & 57.74 & 56.97 & & 53.05 & 51.30 & & 60.55 & 57.69 & & \\
\hline Dönem* & & $57.36 \mathrm{a}$ & & & $52.18 \mathrm{~b}$ & & & $59.12 \mathrm{a}$ & & \\
\hline \multicolumn{11}{|c|}{ Meyve et rengi chroma değeri ${ }^{\mathrm{e}}$} \\
\hline \multirow{2}{*}{ Ortam } & \multicolumn{3}{|c|}{ I. Dönem } & \multicolumn{3}{|c|}{$\begin{array}{l}\text { II. Dönem } \\
\end{array}$} & \multicolumn{3}{|c|}{ III. Dönem } & \\
\hline & Iş1k* & Gölge* & Ort.* & Iş1k* & Gölge* & Ort.* & Iş1k* & Gölge* & Ort.* & Ort. \\
\hline HCL* & $22.3 c$ & $24.8 \mathrm{bc}$ & $23.5 \mathrm{bc}$ & $24.2 \mathrm{bc}$ & $18.3 \mathrm{~d}$ & $21.2 \mathrm{c}$ & $23.3 \mathrm{c}$ & $24.5 b c$ & $23.9 \mathrm{ab}$ & 22.90 \\
\hline KY* & $28.5 a$ & $23.3 \mathrm{c}$ & $25.9 \mathrm{ab}$ & 26.9ab & $25.3 \mathrm{abc}$ & $26.1 \mathrm{a}$ & $24.5 b c$ & $23.6 b c$ & $24.1 \mathrm{ab}$ & 25.40 \\
\hline Ort. & 25.44 & 24.10 & & 25.58 & 21.85 & & 23.93 & 24.13 & & \\
\hline Dönem & & 24.77 & & & 23.71 & & & 24.03 & & \\
\hline
\end{tabular}

Çalışmada yetiştirme dönemleri karşılaştırıldığında; meyve et renginde a değerlerinin en yüksek 14.49 değeri ile 2014 yılı sonbahar döneminde ve $b$ değeri yönünden ise en yüksek değerin 20.83 ile 2014 yılı ilkbahar dikim döneminde gerçekleştiği belirlenmiştir.
Uygulamalar arasında meyve et rengi $a$ ve $b$ değerlerinin interaksiyon gösterdiği ve meyve et renginde a değerinin artarken, $b$ değerinin ise belirgin olarak azaldığ 1 belirlenmiştir. Ortalama meyve et rengi hue $^{\mathrm{o}}$ açısı değerleri istatistiksel olarak analiz 
edildiğinde, uygulamalar arasında $\mathrm{P}<0.05$ 'e göre önemli düzeyde farklılıklar olduğu tespit edilmiştir (Çizelge 5). Meyve et rengi hue ${ }^{\circ}$ açısı değerlerinin, ilkbahar dikim dönemlerinde (57.36-59.12), sonbahar dönemine göre (52.18) daha yüksek olduğu bulunmuştur. Meyve eti chroma değerleri; uygulamalar arasında, dönemxışık interaksiyonu istatistiki olarak önemli $(\mathrm{P}<0.05)$ düzeyde farklılıklar göstermiştir (Çizelge 5). En yüksek chroma değeri, 28.5 ile kayayünü yetiştirme ortamında ve yüksek 1şık koşullarında $26.22^{\circ} \mathrm{C}$ ve $455.93 \mu \mathrm{mol} \mathrm{m}^{-2} \mathrm{~s}^{-1}$ ölçülmüştür. İlkbahar döneminde ortalama chroma değerleri sirasıyla, 24.03-24.77, sonbahar dönemine (23.71) göre daha yüksek olduğu saptanmıştır. Domateslerde meyve eti sertliği ve kabuk direnci ürünün depolanması, dağıtım ve olgunluk süresince değişim gösterdiğinden mekanik zedelenmelere karşı önemli bir hasat kriteridir (Batu, 2004). Meyve eti sertliği bakımından uygulamalar arasında, $\mathrm{P}<0.05$ 'e göre önemli seviyede farklılıklar olduğu saptanmıştır (Çizelge 6). En yüksek meyve eti sertliği, $3.42 \mathrm{~kg} \mathrm{~m}^{-2}$ ile 2014 y1lı sonbahar döneminde yetiştirilen domates meyvelerinde ölçülmüştür. Yetiştirme ortamlarının meyve eti sertliği üzerine etkisi istatistiksel olarak önemsiz düzeyde olmakla birlikte; en yüksek değer, kayayünü yetiştirme ortamınında $\left(2.90 \quad \mathrm{~kg}^{-2}\right)$ saptanmıştır (Çizelge 6). Elde ettiğimiz araştırma sonuçları, Kılıç (2014) ile Toprak ve Gül (2013) tarafından yapılan çalışma sonuçlarıyla benzerlik göstermiştir. Her iki çalışmada da inorganik substratlarda yetiştirilen domates meyvelerinde kabuk direncinin daha yüksek değerlerde olduğu tespit edilmiştir.

Çizelge 6. Farklı ışık ve sıcaklık şartlarında değişik ortamlarda yetiştirilen salkım domateslerde meyve eti sertliği değerlerinin değişimi $\left(\mathrm{kg} \mathrm{m}^{-2}\right)(* \mathrm{P}<0.05, \mathrm{CV}: \% 6.5)$

\begin{tabular}{lcccccccccc}
\hline \multirow{2}{*}{ Substrat } & \multicolumn{3}{c}{ I. Dönem } & \multicolumn{3}{c}{ II. Dönem } & \multicolumn{3}{c}{ III. Dönem } \\
\cline { 2 - 10 } & Iş1k* & Gölge* & Ort. & Iş1k* & Gölge* & Ort. & Iş1k* & Gölge* & Ort. & Ort. \\
\hline HCL & $2.76 \mathrm{cde}$ & $1.96 \mathrm{~h}$ & 2.36 & $3.14 \mathrm{~b}$ & $3.56 \mathrm{a}$ & 3.35 & $2.53 \mathrm{def}$ & $2.36 \mathrm{fg}$ & 2.45 & 2.72 \\
KY & $2.93 \mathrm{bc}$ & $2.50 \mathrm{ef}$ & 2.71 & $3.50 \mathrm{a}$ & $3.50 \mathrm{a}$ & 3.50 & $2.84 \mathrm{bcd}$ & $2.13 \mathrm{gh}$ & 2.48 & 2.90 \\
Ort.* & $2.84 \mathrm{~b}$ & $2.23 \mathrm{c}$ & & $3.32 \mathrm{a}$ & $3.53 \mathrm{a}$ & & $2.68 \mathrm{~b}$ & $2.50 \mathrm{c}$ & & \\
\hline Dönem* & \multicolumn{3}{c}{$2.53 \mathrm{~b}$} & & & $3.42 \mathrm{a}$ & \multicolumn{5}{c}{$2.46 \mathrm{~b}$} \\
\hline
\end{tabular}

Domates meyvelerinde suda çözünür kuru madde miktarı, meyve lezzetini oluşturan en önemli meyve kalite bileşenlerindendir (Özkaplan, 2018). Çalışmada, SÇKM değeri en yüksek, \%100 doğal 1şık altında yetiştirilen domateslerde $(\% 5.66)$ ve en düşük $\% 50$ gölgeleme uygulamasında (\%4.08) elde edilmiştir (Çizelge 7). Birçok araştırma sonucu, domates meyvelerinde artan 1 şık ve sıcaklık koşullarının \%
SÇKM değerini arttırdığını göstermiştir (El-Gizawy ve ark., 1993 ve Demirsoy, 2016). Tüzel ve ark. (2009) domates meyvelerinde \% SÇKM değerinin \%3.7-4.9; Bonakdarzadeh (2014), \%4.08-4.40; Y1ld1z (2013), \%4.27-4.60; Dönmez (2015), \%6.03-6.73 aralığında değişim gösterdiğini bildirmişlerdir. Araştırma sonuçları, belirtilen literatürleri destekler nitelikte olmuştur.

Çizelge 7. Farklı 1şık ve sıcaklık şartlarında değişik ortamlarda yetiştirilen salkım domateslerde suda çözünür kurumadde değerleri (\%) (SÇKM) $(* \mathrm{P}<0.05, \mathrm{CV}: \% 3.1)$

\begin{tabular}{lcccccccccc}
\hline \multirow{2}{*}{ Substrat } & \multicolumn{3}{c}{ I. Dönem } & \multicolumn{3}{c}{ II. Dönem } & \multicolumn{3}{c}{ III. Dönem } \\
\cline { 2 - 11 } & Işık & Gölge & Ort. & Işık & Gölge & Ort. & Iş1k & Gölge & Ort. & Ort. \\
\hline HCL & 5.40 & 4.76 & 5.08 & 4.73 & 4.00 & 4.36 & 5.73 & 4.80 & 5.26 & 4.90 \\
KY & 5.30 & 4.70 & 5.00 & 4.53 & 4.16 & 4.35 & 5.60 & 4.63 & 5.11 & 4.82 \\
Ort.* & $5.35 \mathrm{~b}$ & $4.73 \mathrm{c}$ & & $4.63 \mathrm{c}$ & $4.08 \mathrm{~d}$ & & $5.66 \mathrm{a}$ & $4.71 \mathrm{c}$ & & \\
\hline Dönem* & \multicolumn{3}{c}{$5.04 \mathrm{~b}$} & & & $4.35 \mathrm{c}$ & & \multicolumn{5}{c}{$5.19 \mathrm{a}$} & \\
\hline
\end{tabular}

Titre edilebilir asitlik, domates meyvelerinde önemli bir lezzet bileşenidir. Çalışmada domates bitkilerinin yetiştirme dönemlerine göre TA değerlerinde önemli düzeyde $\quad(\mathrm{P}<0.05) \quad$ farkl1l1klar gösterdikleri belirlenmiştir. Ayrıca, dikim zamanlarına göre domates meyvelerinde TA'nın en fazla \%0.40 ile 2014 y1lı sonbahar döneminde olduğu tespit edilmiştir. Elde edilen bulgulara göre; azalan 1şık şiddetinin titre edilebilir asit değerlerini arttırdığı saptanmıştır. 2014 y1lı sonbahar yetiştirme döneminde, $\% 50$ gölge uygulamas1 altında titre edilebilir asitlik oranı, Hindistan cevizi lifi uygulamalarında en yüksek bulunmuştur. Çalışmada domates meyvelerinde titre edilebilir asitlik değerlerinin düşük ışık koşulları altında artış gösterdiği belirlenmiştir (Çizelge 8). El-Gizawy ve ark. (1993) ve Demirsoy (2016) domates meyvelerinde TA oranının, ilkbahar dönemine göre sonbaharda en yüksek değere ulaştı̆̆ını bildirmiş ve bu bulgular çalışmamızı destekler nitelikte olmuştur. Şahin ve ark. (1998), torf yetiştirme ortamından elde edilen domates meyvelerinde titre edilebilir asitlik oranının \%0.47-0.48; Ünlü ve Padem (2009) ise \%0.23-0.43 arasında değişim gösterdiğini belirtmişlerdir. Kılıç (2014), farklı yetiştirme ortamlarından elde edilen domates 
meyvelerinde en yüksek TA değerlerinin Hindistan cevizi lifi ortamından (\%0.43) elde ettiğini bildirmiştir.

Domateste meyve suyundaki $\mathrm{pH}$, tadi belirleyen önemli kalite parametrelerinden birisidir. Genel olarak kalite analizlerinde, düşük $\mathrm{pH}$ değeri (2.0 civarı) ekşi meyveleri, düşük asitlik değeri ise tatlı meyveleri ifade eder (Brown, 2007). Araştırmada meyve suyundaki
pH'nın ortam, dönem ve ortamxış1k interaksiyonunda çok önemli düzeyde farklılıklar gösterdiği belirlenmiştir. En yüksek meyve suyu pH's1 4.39 ile ilkbahar döneminde (2015 yılı) tespit edilmiştir (Çizelge 9). Elde edilen bulgulara göre, artan 1șı1k şiddetin meyve suyu pH değerini artırdığı belirlenmiştir (Yıldız, 2013; Demirsoy, 2016).

Çizelge 8. Farklı ışık ve sıcaklık şartlarında değişik ortamlarda yetiştirilen salkım domateslerde titre edilebilir asitlik (\%) (TA) değerleri (*P<0.05, CV: \%3.2)

\begin{tabular}{lcccccccccc}
\hline \multirow{2}{*}{ Substrat } & \multicolumn{3}{c}{ I. Dönem } & \multicolumn{3}{c}{ II. Dönem } & \multicolumn{3}{c}{ III. Dönem } \\
\cline { 2 - 11 } & Işık & Gölge & Ort.* & Işı & Gölge & Ort.* & Işı & Gölge & Ort.* & Ort.* \\
\hline HCL & 0.32 & 0.44 & $0.38 \mathrm{~b}$ & 0.36 & 0.45 & $0.40 \mathrm{a}$ & 0.33 & 0.42 & $0.37 \mathrm{~b}$ & $0.38 \mathrm{a}$ \\
KY & 0.29 & 0.37 & $0.33 \mathrm{c}$ & 0.37 & 0.43 & $0.40 \mathrm{a}$ & 0.29 & 0.36 & $0.33 \mathrm{~b}$ & $0.35 \mathrm{~b}$ \\
Ort.* & $0.30 \mathrm{~d}$ & $0.40 \mathrm{~b}$ & & $0.36 \mathrm{c}$ & $0.44 \mathrm{a}$ & & $0.31 \mathrm{~d}$ & $0.39 \mathrm{~b}$ & & \\
\hline Dönem* & \multicolumn{3}{c}{$0.35 \mathrm{~b}$} & \multicolumn{3}{c}{$0.40 \mathrm{a}$} & \multicolumn{5}{c}{$0.35 \mathrm{~b}$} & \\
\hline
\end{tabular}

Çizelge 9. Farklı 1şık ve sıcaklık şartlarında değişik ortamlarda yetiştirilen salkım domateslerde pH değerlerinin değişimi (*P<0.05, CV: \%3.6)

\begin{tabular}{lcccccccccc}
\hline \multirow{2}{*}{ Substrat } & \multicolumn{3}{c}{ I. Dönem } & \multicolumn{3}{c}{ II. Dönem } & \multicolumn{3}{c}{ III. Dönem } \\
\cline { 2 - 11 } & Işı & Gölge & Ort & Işı & Gölge & Ort & Işı & Gölge & Ort & Ort.* \\
\hline HCL & 4.43 & 4.06 & 4.25 & 3.92 & 3.96 & 3.94 & 4.60 & 4.10 & 4.35 & $4.18 \mathrm{~b}$ \\
KY & 4.41 & 4.10 & 4.25 & 4.16 & 4.20 & 4.18 & 4.63 & 4.23 & 4.43 & $4.29 \mathrm{a}$ \\
Ort* & $4.42 \mathrm{~b}$ & $4.08 \mathrm{c}$ & & $4.04 \mathrm{c}$ & $4.08 \mathrm{c}$ & & $4.61 \mathrm{a}$ & $4.16 \mathrm{c}$ & & \\
\hline Dönem* & \multicolumn{3}{c}{$4.25 \mathrm{~b}$} & \multicolumn{3}{c}{$4.06 \mathrm{c}$} & \multicolumn{5}{c}{$4.39 \mathrm{a}$} & \\
\hline
\end{tabular}

Benzer bir şekilde Tüzel ve ark. (2009) domates meyvelerinde, meyve suyu $\mathrm{pH}$ değerinin 4.2-4.3, Bozköylü ve Daşgan (2010) 4.3-4.4; Toprak ve Gül (2013), 4.52-4.66; Kirac1 ve Karataş (2015) 4.37-4.58; aralığında değişim gösterdiğini bildirmişlerdir.

Domates meyvelerinin EC içeriği bakımından, substratlar arasında istatistiksel olarak $(\mathrm{P}<0.05)$ önemli düzeyde farkl1lıklar olduğu bulunmuştur. En yüksek meyve suyu EC değeri, $5.04 \mathrm{ds} \mathrm{m}^{-1}$ ile Hindistan cevizi lifinden elde edilmiştir (Çizelge 10 ). Üç farklı dikim döneminde içerisinde, en yüksek meyve suyu EC değerleri $5.16 \quad \mathrm{ds}^{-1}$ ile 2014 y1lı ilkbahar yetiştiriciliğinde elde edilmiştir. İlkbahar yetiştiriciliğinde gölgelemenin etkisiyle azalan $1 s ̧ 1 \mathrm{k}$ şiddeti meyve suyunda EC değerinin artmasına neden olmuştur. Ancak, sonbahar yetiştirme döneminde ise artan 1şık şiddeti meyve suyu EC değerini arttırıcı yönde etki yapmıştır. Tüzel ve ark. (2009) domates meyvelerinde meyve suyu EC değerinin $4.5 \mathrm{ds} \mathrm{m}^{-1}$ ile $5.9 \mathrm{ds} \mathrm{m}^{-1}$ arasında değiştiğini; Bozköylü ve Daşgan (2010), domateslerde meyve suyunda en düşük EC değerinin $2.7 \mathrm{ds} \mathrm{m}^{-1}$, en yükssek ise $3.2 \mathrm{ds} \mathrm{m}^{-1}$ olduğunu belirtmişlerdir. Toprak ve Gül (2013), domateste en yüksek meyve suyu pH'sının Hindistan cevizi lifi büyüme ortamında $5.84 \mathrm{ds} \mathrm{m}^{-1}$ iken perlit ortamında 4.54 ds $\mathrm{m}^{-1}$ olduğunu bildirmişlerdir.

Çizelge 10. Farklı 1şık ve sıcaklık şartlarında değişik ortamlarda yetiştirilen salkım domateslerde EC (ds $\mathrm{m}^{-1}$ ) değerleri $(* \mathrm{P}<0.05, \mathrm{CV}: \% 3.3)$

\begin{tabular}{lcccccccccc}
\hline \multirow{2}{*}{ Substrat } & \multicolumn{3}{c}{ I. Dönem } & \multicolumn{3}{c}{ II. Dönem } & \multicolumn{3}{c}{ III. Dönem } \\
\cline { 2 - 10 } & Iş1k* & Gölge* & Ort.* & Iș1k* & Gölge* & Ort.* & Iş1k* & Gölge* & Ort.* & Ort.* \\
\hline HCL & $5.10 \mathrm{c}$ & $5.62 \mathrm{a}$ & $5.36 \mathrm{a}$ & $5.08 \mathrm{c}$ & $4.47 \mathrm{e}$ & $4.77 \mathrm{de}$ & $4.76 \mathrm{~d}$ & $5.20 \mathrm{bc}$ & $4.98 \mathrm{bc}$ & $5.04 \mathrm{a}$ \\
$\mathrm{KY}$ & $4.49 \mathrm{de}$ & $5.43 \mathrm{ab}$ & $4.96 \mathrm{~cd}$ & $4.67 \mathrm{de}$ & $4.56 \mathrm{de}$ & $4.62 \mathrm{e}$ & $5.06 \mathrm{c}$ & $5.28 \mathrm{bc}$ & $5.17 \mathrm{ab}$ & $4.92 \mathrm{~b}$ \\
Ort.* & $4.80 \mathrm{c}$ & $5.53 \mathrm{a}$ & & $4.87 \mathrm{c}$ & $4.52 \mathrm{~d}$ & & $4.91 \mathrm{c}$ & $5.24 \mathrm{~b}$ & & \\
\hline Dönem* & \multicolumn{3}{c}{$5.16 \mathrm{a}$} & \multicolumn{3}{c}{$4.69 \mathrm{~b}$} & \multicolumn{5}{c}{$5.08 \mathrm{a}$} \\
\hline
\end{tabular}

\section{Sonuç}

Araştırma sonucunda; sıcaklık, 1şı̂k değerleri ve substratların domateste meyve kalitesi üzerine önemli düzeyde etkiler oluşturduğu saptanmıştır. Artan ışık yoğunluğu ve sıcaklık koşullarında hem meyve boyu hemde meyve çapı değerleri belirgin düzeyde artışlar olduğu bulunmuştur. Meyve boyutları yönünden yapılan değerlendirmede; ilkbahar yetiştirme dönemlerinde meyve boyutlarının sonbahar dönemine göre daha yüksek olduğu tespit edilmiştir. Meyve şekil indeksi değerleri ise yetiştirme dönemlerine göre farklılık 
göstermiştir. Ayrıca, sıcaklık ve 1şık şiddetinin, meyve şekil indeksi değerlerini olumlu yönde etkilediği belirlenmiştir. Genel olarak Hindistan cevizi lifi substratının, meyve kabuk rengi; L, a, b, hue ${ }^{\circ}$, chroma* değerleri üzerine etkilerinin olumlu olduğu belirlenmiştir. Artan sıcaklık ve 1şık şiddetinin, domateste \% SÇKM değerini artırdığ 1 saptanmıştır. Ayrıca düşük ışık koşullarının domates meyvelerinde, titre edilebilir asit değerlerini artırdığı tespit edilmiştir. Özellikle sonbahar döneminde hasat edilen meyvelerde ilkbahar dönemine göre titre edilebilir asit değerlerinin daha yüksek olduğu belirlenmiştir. Genel anlamda artan ışık yoğunluğu ve sıcaklık koşullarının meyve kalite parametrelerini olumlu yönde etkilediği saptanmıştır. Çalışmada, Hindistan cevizi lifi uygulamalarının meyve kalite unsurlarını olumlu yönde etkilediği belirlenmiştir.

Meyve albenisini oluşturan meyve kabuk rengi parlaklığı, canlılığ ve doygunluğu bakımından Hindistan cevizi lifi substartının yetiştirme ortamı olarak öne çıktı̆̆ı ancak meyve eti sertliğinin bakımından en sert meyvelerin kayayünü substratlarında olduğu belirlenmiştir. Topraksız tarım domates yetiştiriciliğinde meyve kalitesi üzerine kullanılan substratlar kadar 1şık ve sıcaklık da oldukça önemli bir etkiye sahiptir. Özellikle domates gibi ışık ve sıcaklık isteği yüksek olan bitkilerde iyi bir planlama ile kontrollü ışı ve sıcaklık koşulları altında daha kaliteli ürünler elde edilebilir. Elde edilen bu sonuçlar, ülkemizde topraksız tarım teknikleri kullanılarak yapılacak domates yetiştiriciliğinde üretim planlaması yapılmasında önemli yararlar sağlayacaktır.

\section{Teșekkür}

$\mathrm{Bu}$ çalışma; Ondokuz Mayıs Üniversitesi Bilimsel Araştırma Fonu (PYO.ZRT.1904.13.024) tarafindan desteklenmiştir. Merhum Prof. Dr. Sezgin Uzun'a doktora tez çalışmasının başlangıcında yapmış olduğu fikri katkılarından dolayı teşekkür ederim.

\section{Kaynaklar}

Balkaya, A., Özcan, M., 1997. Sebzelerde kalite ve kaliteyi etkileyen faktörler. Bahçe Ürünlerinde Muhafaza ve Pazarlama Sempozyumu, 295-311, 21 24 Ekim, Yalova.

Batu, A., 2004. Determination of acceptable firmness and colour values of tomatoes. Journal Food Engineering, 61(3): 471-475.

Borji, H., Ghahsareh, A. M., Jafarpour, M., 2010. Effects of the substrate on tomato in soilless culture. Research Journal of Agriculture and Biological Sciences, 6(6): 923-927.

Bonakdarzadeh, M., 2014. Topraksız tarımda farklı domates çeşitlerinin meyve kalite özelliklerinde mevsimsel değişimler. Yüksek Lisans Tezi. Ege Üniversitesi Fen Bilimleri Enstitüsü, 67 s, İzmir.

Bozköylü, A., Daşgan, H., 2010. Sera topraksız domates yetiştiriciliğinde kimyasal ve organik gübrelemenin karşılaştırılması. TÜBAV Bilim Dergisi, 3(2): 174181.

Brown, A., 2007. Understanding food principles and preparation. Thomson Higher Education 10 Davis Drive Belmont, CA 9402- 3098, p 672 , USA.

Cemeroğlu, B., 2007. Gıda analizleri. Gida Teknolojisi Derneği Yayınları, No:34, Bizim Büro Basımevi, $535 \mathrm{~s}$, Ankara.

Cockshull, K.E., Graves, C.J. and Carol R.J., 1992. The influence of shading on yield of glasshouse tomatoes. Journal of Horticulturel Science, 67(1): 11-24.

De Koning, A.N.M., 1994. Development and dry matter distrubution in glasshouse tomato quantitive aproach. Thesis, Agriculture University, p 240, Wageningen The Netherlands.

Demirsoy, M., 2016. Sera koşullarında farklı yapay ışık, renk ve kaynaklarının (Lycopersicon esculentum Mill.), biber (Capsicum annuum L.) ve patlicanda (Solanum melongena L.) fide büyüme, gelişme, kalite ve dikim sonrası adaptasyonlarına etkilerinin kantitatif yöntemlerle incelenmesi. Ondokuz Mayis Üniversitesi Fen Bilimleri Enstitüsü, 157s, Samsun.

Demirtaş EI, Asri Ö.F., Özkan C.F., Arı N., 2012. Organik ve kimyasal gübre uygulamalarının örtüaltı domates yetiştiriciliğinde toprak verimliliği ve bitkinin beslenmesine etkileri. Batı Akdeniz Tarımsal Araştırma Enstitüsü Derim Dergisi, 29(1): 9-22.

Dorais, M., Papadopoulos, A.P., Gosselin, A., 2001. Greenhouse tomato fruit quality. Horticultural Reviews, 26: 239-319.

Dönmez, İ., 2015. Bazı bölgesel organik atıkların topraksız tarımda (torba kültürü) kullanılabilme imkanlarının belirlenmesi. Yüksek Lisans Tezi. Ondokuz Mayıs Üniversitesi Fen Bilimleri Enstitüsü, 73s. Samsun.

El-Gizawy, A.M., Gomaa, H.M., El-Habbasha, K.M. and Mohamed, S.S., 1993. Effect of different shading levels on tomato plants. 1. Growth, Flowering and Chemical Composition. Acta Horticulturae, 323, 341-348.

Fandi, M., Muhtaseb, J., Hussein, M., 2007. Effect of plant density on tomato yield and fruit quality growing in tuff culture. Acta Horticulturae. 741, 207-212.

FAO, 2017. Food and agriculture organizatioan. URL: http://www.fao.org/faostat/en/\#data/QC (Erişim tarihi: 04.03.2019).

Geboloğlu, N., Yıldız, D., 2013. Gölgelemenin sırık domates yetiştiriciliğinde verim, kalite ve bazı argonomik özellikler üzerine etkisi. Gaziosmanpaşa Üniversitesi Bilimsel Araştırmalar Projeleri Komisyonu Sonuç Raporu, Proje No: 2012/83.

Gül, A., 2008. Topraksız Tarım. Hasad Yayıncılık, 144 s. İstanbul.

Güneş, A., İnal, A., Karaman, M.R., Geboloğlu, N., 2012. Topraksız yetiştiricilik sisteminde bitki 
besleme yöntemi. Bitki Besleme. Gübretaş Rehber Kitaplar Dizisi: 2. 1066 s.

Kandemir, D., Kurtar, S.E., Demirsoy, M., 2016. Türkiye örtüaltı domates yetiştiriciliğindeki gelişmeler. Türkiye Tohumcular Birliği Dergisi, 5(17): 22-27.

Karaağaç, O., 2013. Karadeniz Bölgesi'nden toplanan kestane kabağı (C. maxima) ve bal kabağ (C.moschata) genotiplerinin karpuza anaçlık potansiyellerinin belirlenmesi. Doktora Tezi, Ondokuz Mayıs Üniversitesi, Fen Bilimleri Enstitüsü, 240 s, Samsun.

Karaağaç, O., Balkaya, A., Kafkas, N.E., 2018. Karpuzda (Citrullus lanatus) meyve kalitesi ve aroma özellikleri üzerine anaçların etkisi. Anadolu Tarım Bilimleri Dergisi, 33: 92-104.

Kaya, S., 2012. Yerel sofralık domates populasyonlarının organik tarıma uygunlukları ve organik çeşit geliştirme amacıyla kullanım olanakları üzerine araştırmalar. Ege Üniversitesi Fen Bilimleri Enstitüsü. $111 \mathrm{~s}$. İzmir.

Kılıç, P., 2014. Topraksız domates yetiştiriciliğginde kullanılan farklı ortamların verim, kalite ve bitki besin elementi tüketimi üzerine etkileri. Süleyman Demirel Üniversitesi. Fen Bilimleri Enstitüsü, 69 s. Isparta.

Kirac1, S. ve Karataş, A., 2015. Organik domates yetiştiriciliğinde bitki aktivatörü uygulamalarının verim ve kalite üzerine etkisi. Adnan Menderes Üniversitesi Ziraat Fakültesi Dergisi, 12(1), 17-22.

Leonardi, C., 2004. Growing media. Regional Training Workshop On Soilless Culture Technologies. 3-5 March, 83-92, İzmir.

Leonardi, C., Kyriacou, M., Gisbert, C., Oztekin, G.B., Mourão, I., Rouphael, Y., 2017. Quality of grafted vegetables. In: Colla, G., Pérez-Alfocea F., Schwarz, D. (Eds). Vegetable Grafting: Principles and Practices. CAB International. pp. 216-244, Oxfordshire, UK.

Lopez Camelo, A.F., Gomez, P. A., 2004. Comparasion of color indexes for tomato ripening. Horticultura Brasileira, 22(3): 534-537.

Matas, A.J., Gapper, N.E., Chung,Mi-Y., Giovannoni, J.J., Rose, J.K.C., 2009. Biology and genetic engineering of fruitmaturation for enhanced quality and shelf-life. Current Opinion in Biotechnology. 20, 197-203.

Mcguire, R.G., 1992. Reporting of objective color measurements, HortScience, 27, 1254-1255.

Nichols, M.A., 2002. Strawberry tip runners. Practical Hydroponics and Greenhouses, 64, 34-50.

Nothmann, J., 1986. Fruiting of eggplant in a mild winter climate. Acta Horticulture. 191, 237-246.

Özkaplan, M., 2018. Serada topraksiz domates yetiştiriciliğinde büyüme, gelişme ve verim üzerine ışik ve sıcaklığın kantitatif etkilerinin modellenmesi. Ondokuz Mayıs Üniversitesi Fen Bilimleri Enstitüsü, 238 s, Samsun.
Pardossi, A., Carmassi, G., Diara, C., Incrocci, L., Maggini, R., Massa, D., 2011. Efficient use of inputs in protected horticulture. Department of Biologicial Agriculture, University of Pisa, p 260, Italy.

Pearson, S., 1992. Modelling the effect of temperature on the growth and development of horticultural crops. Unpublished $\mathrm{PhD}$ thesis, Reading University, England, 204 pp.

Peet, M. M. and Heuvelink, E., (Ed.). 2005. Irrigation and fertilization in tomatoes. Cabi Publishing. pp. 198, Wallingford, U.K.

Prasad, L. B., Babu Adhikari, P., Soo Yoon, C., Hee Kang, W., 2012. Yield and fruit quality of tomato (Lycopersicon esculentum Mill.) cultivars established at different planting bed size and growing substrates. Horticulture, Environment and Biotechnology, 53, 102-107.

Radzevičius, A., Karkleliene, R., Viškelis, P., Bobinas, C., Bobinaitè, R., Sakalauskienè, S., 2009. Tomato (Lycopersicon esculentum Mill.) fruit quality and physiological parameters at different ripening stages of; Lithuanian cultivars. Agronomy Research, 7 (Special issue II): 712-718.

Sezen, S. M., G. Celikel, A. Yazar, S. Tekin and Kapur, B., 2010. Effect of irrigation management on yield and quality of tomatoes grown in different soilless media in a glasshouse. Scientific Research and Essay. 5, 041-048.

Sönmez, K., Ellialtığlu, Ş.Ş., 2014. Domates, karotenoidler ve bunları etkileyen faktörler üzerine bir inceleme. Derim, 31 (2):107-130.

Şahin, Ü., Özdeniz, A., Zülkadir, A., Alan, R., 1998. Sera koşullarında damla sulama yöntemi ile sulanan domates (Lycopersicon esculentum Mill.) bitkisinde farklı yetiştirme ortamlarının verim, kalite ve bitki gelişmesine olan etkileri. Journal of Agriculture and Forestry. (22), 71-79.

TÜIK, 2018. Türkiye İstatistik Kurumu. www.tüik.gov.tr

URLhttps://biruni.tuik.gov.tr/medas/?kn=92\&locale $=\operatorname{tr}($ Erişim tarihi: 04.03.2019).

Tüzel, Y., Duyar, H., Öztekin, G.B., Gül, A., 2009. Domates anaçlarının farklı dikim tarihlerinde bitki gelişimi, sıcaklık toplamı isteği, verim ve kaliteye etkileri. Ege Üniversitesi Ziraat Fak. Dergisi, 46 (2): 79-92.

Toprak, E., Gül A., 2013. Topraksız tarımda kullanılan ortam domates verimi ve kalitesini etkiliyor mu? Tarım Bilimleri Araştırma Dergisi, 6 (2): 41-47.

Uzun, S., Demir, Y., 1996. Sicaklık ve 1şı̆̆ın bitki büyüme, gelişme ve verimine etkisi. (II. Gelişme). OMÜ Ziraat Fakültesi Dergisi, 11(3): 201-212.

Uzun, S., 2000. Sicaklık ve ışığın bitki büyüme, gelişme ve verimine etkisi (III. Verim). Ondokuz Mayis Üniversitesi Ziraat Fakültesi Dergisi, 15(1): 105108.

Uzun, S., 2007. Effect of light and temperature on the phenology and maturation of the fruit of eggplant (Solanum melongena) grown in greenhouses. New 
Zealand Journal of Crop and Horticultural Science, 35, 51-59.

Ünlü, H., Padem, H., 2009. Organik domates yetiştiriciliğinde çiftlik gübresi, mikrobiyal gübre ve bitki aktivatörü kullanımının verim ve kalite özellikleri üzerine etkileri. Ekoloji Dergisi, 19(73):19.

Yıldız, D., 2013. Gölgelemenin sırık domates yetiştiriciliğinde verim, kalite ve bazı argonomik özellikler üzerine etkisi. Yüksek Lisans Tezi. Gaziosmanpaşa Üniversitesi Fen Bilimleri Enstitüsü, $44 \mathrm{~s}$, Tokat.

Young, T. E., Juvik J. A., Sullivan J. G., 1993. Accumulation of the components of total solids in ripening fruits of tomato. Journal of the American Society for Horticultural Science. 112: 286-292. 